\title{
Feasibility of CT quantification of intratumoural ${ }^{166} \mathrm{Ho}$-microspheres
}

\author{
R. C. Bakker ${ }^{1,2^{*}}$, R. Bastiaannet ${ }^{1}$, S. A. van Nimwegen ${ }^{3}$, A. D. Barten-van Rijbroek ${ }^{1}$, R. J. J. Van Es ${ }^{2,4}$ \\ A. J. W. P. Rosenberg' ${ }^{2}$, H. W. A. M. de Jong ${ }^{1}$, M. G. E. H. Lam ${ }^{1}$ and J. F. W. Nijsen ${ }^{5}$
}

\begin{abstract}
Background: Microspheres loaded with radioactive ${ }^{166} \mathrm{Ho}\left({ }^{166} \mathrm{Ho}-\mathrm{MS}\right)$ are novel particles for radioembolisation and intratumoural treatment. Because of the limited penetration of $\beta$ radiation, quantitative imaging of microsphere distribution is crucial for optimal intratumoural treatment. Computed tomography (CT) may provide high-resolution and fast imaging of the distribution of these microspheres, with lower costs and widespread availability in comparison with current standard single-photon emission tomography (SPECT) and magnetic resonance imaging. This phantom study investigated the feasibility of CT quantification of ${ }^{166} \mathrm{Ho}-\mathrm{MS}$.

Methods: CT quantification was performed on a phantom with various concentrations of $\mathrm{HoCl}$ and $\mathrm{Ho}-\mathrm{MS}$ to investigate the CT sensitivity and calibrate the CT recovery. ${ }^{166} \mathrm{Ho}$-MS were injected into ex vivo tissues, in VX-2 cancer-bearing rabbits, and in patients with head-neck cancer, to demonstrate sensitivity and clinical visibility. The amount of Ho-MS was determined by CT scanning, using a density-based threshold method and compared with a validated ${ }^{166} \mathrm{HO}$ SPECT quantification method.

Results: In the phantom, a near perfect linearity (least squares $R^{2}>0.99$ ) between $\mathrm{HU}$ values and concentration of ${ }^{166} \mathrm{Ho}$ was found. Ex vivo tissue experiments showed an excellent correlation $(r=0.99, p<0.01)$ between the dose calibrator, SPECT, and CT imaging. CT recovery was on average $86.4 \%$ ex vivo, $76.0 \%$ in rabbits, and $99.1 \%$ in humans.

Conclusion: This study showed that CT-based quantification of Ho microspheres is feasible and is a high-resolution alternative to SPECT-based determination of their local distribution.
\end{abstract}

Keywords: Brachytherapy, Head and neck neoplasms, Humans, Radioisotopes, Tomography (x-ray computed)

\section{Key points}

- Microspheres loaded with radioactive ${ }^{166} \mathrm{Ho}$ (166Ho-MS) are novel particles for radioembolisation and intratumoural treatment.

- A phantom study showed a near perfect linearity between $\mathrm{HU}$ values on computed tomography (CT) images and concentration of ${ }^{166} \mathrm{Ho}$.

\footnotetext{
* Correspondence:

${ }^{1}$ Department of Radiology and Nuclear Medicine, University Medical Center Utrecht, Utrecht, The Netherlands

${ }^{2}$ Department of Oral and Maxillofacial Surgery, University Medical Center Utrecht, Utrecht, The Netherlands

Full list of author information is available at the end of the article
}

- CT recovery was on average $86.4 \%$ ex vivo, $76.0 \%$ in rabbits, and 99.1\% in humans.

- CT can provide fast, high-resolution, and threedimensional information on the distribution of ${ }^{166} \mathrm{Ho}-\mathrm{MS}$ for future anti-cancer therapy.

\section{Background}

A relatively new oncological treatment option is selective internal radiation therapy using small radioactive particles, also called radioembolisation. Radioactive holmium-166 $\left({ }^{166} \mathrm{Ho}\right)$-loaded (poly L-lactic acid) microspheres $\left({ }^{166} \mathrm{Ho}-\right.$ MS) were developed for radioembolisation of liver tumours through intra-arterial injection [1]. These ${ }^{166} \mathrm{Ho}-\mathrm{MS}$ have a mean diameter of $30 \mu \mathrm{m}$ and emit high-energy $\beta$ particles

\section{Springer Open}

(c) The Author(s). 2020 Open Access This article is licensed under a Creative Commons Attribution 4.0 International License, which permits use, sharing, adaptation, distribution and reproduction in any medium or format, as long as you give appropriate credit to the original author(s) and the source, provide a link to the Creative Commons licence, and indicate if changes were made. The images or other third party material in this article are included in the article's Creative Commons licence, unless indicated otherwise in a credit line to the material. If material is not included in the article's Creative Commons licence and your intended use is not permitted by statutory regulation or exceeds the permitted use, you will need to obtain permission directly from the copyright holder. To view a copy of this licence, visit http://creativecommons.org/licenses/by/4.0/. 
for tumour treatment and also $\gamma$ radiation, which allows for quantitative single-photon emission computed tomography (SPECT) imaging $[2,3]$. In addition, Ho is paramagnetic, which potentially allows for using magnetic resonance imaging for its recovery (MRI). Both imaging modalities are used in radioembolisation to investigate the ${ }^{166} \mathrm{Ho}-\mathrm{MS}$ distribution $[1,3,4]$.

The intratumoural injection of radioactive microparticles might be beneficial for selected patients with tumours that can be reached with a needle [5-8]. This kind of "micro-brachytherapy" might have advantages, including minimally invasive handling, outpatient treatment, and potentially improved (progression-free) survival and quality of life $[5,8,9]$. In patients with unresectable hepatocellular carcinoma, 12 weeks after intratumoural injection of radioactive ${ }^{32} \mathrm{P}$-microparticles treatment, all tumours showed response with a complete remission in $25 \%$ of the lesions [7]. The first experience with ${ }^{166}$ Ho-MS in recurrent head and neck cancer patients showed the minimally invasive character and relative safety of this treatment. However, it also revealed challenges in obtaining a homogeneous absorbed dose and sufficient tumour coverage [8].

Intratumoural treatment with ${ }^{166} \mathrm{Ho}-\mathrm{MS}$ has also been conducted in several animal studies [6, 10-12]. In 13 companion animals (cats) with spontaneous inoperable oral squamous cell carcinomas, a local response rate of $55 \%$ was obtained with minimal side effects [6]. The distribution of ${ }^{166} \mathrm{Ho}-\mathrm{MS}$ in these animals was imaged with planar scintigraphy in the absence of SPECT or MRI. During the follow-up, computed tomography (CT) imaging clearly showed the distribution of these microspheres [6].

Thus, CT imaging could offer a quicker and higherresolution feedback on the three-dimensional (3D) distribution of ${ }^{166} \mathrm{Ho}-\mathrm{MS}$ compared to SPECT and MRI, apart from being more widely available and at relatively lower cost. CT scanning may be used to confirm that a homogeneous absorbed dose and sufficient tumour coverage was achieved and eventually facilitate an image-guided treatment approach. The purpose of this study was to assess the feasibility of ${ }^{166} \mathrm{Ho}$-MS quantification using CT.

\section{Methods}

\section{${ }^{166}$ Ho-MS preparation}

Non-radioactive ${ }^{165} \mathrm{Ho}-\mathrm{MS}$ were prepared as previously described [13]. Neutron activation of the Ho-loaded microspheres was performed via the ${ }^{165} \mathrm{Ho}$ (n, y) ${ }^{166} \mathrm{Ho}$ reaction in a nuclear reactor with a nominal thermal neutron flux of $5 \times 10^{12} \mathrm{~cm}^{-2} \mathrm{~s}^{-1}$ (Delft University of Technology). Therefore, vials with known amounts of ${ }^{165} \mathrm{Ho}-\mathrm{MS}$ were irradiated up to $2 \mathrm{~h}$. After neutron activation, ${ }^{166} \mathrm{Ho}-\mathrm{MS}$ emit $\beta$ radiation for tumour ablation
$\left(E_{\beta, \max }=1.84 \mathrm{MeV}\right)$ and $\gamma$ radiation for imaging $\left(E_{\gamma}\right.$ $80.6 \mathrm{keV}, 6.71 \%)$ and has a half-life time of $26.8 \mathrm{~h}$. In the in vitro, ex vivo and rabbit experiments, a batch of $18.7 \%$ weight by weight (Quiremspheres) was used, and in the human patients, a batch of ${ }^{166} \mathrm{Ho}-\mathrm{MS}$ with a Ho content of $17.6 \%$ weight by weight was used, corresponding to approximately $1 \mathrm{mg}$ of Ho per $5.5 \mathrm{mg}{ }^{166} \mathrm{Ho}-\mathrm{MS}$.

\section{Phantom calibration for CT imaging}

To quantify ${ }^{165} \mathrm{Ho}-\mathrm{MS}$ on $\mathrm{CT}$ imaging, series of $\mathrm{HoCl}_{3}$ and ${ }^{165} \mathrm{Ho}-\mathrm{MS}$ concentrations were made to create a calibration curve. A serial dilution $(n=10)$ of $\mathrm{HoCl}_{3}$ hexahydrate $\left(\mathrm{HoCl}_{3} \cdot 6 \mathrm{H}_{2} \mathrm{O}\right)$ (Sigma-Aldrich Chemie N.V., Zwijndrecht, The Netherlands) was made in sterile demineralised water (Versylene, Fresenius Kabi, B.V., Huis Ter Heide, The Netherlands) to obtain a homogeneous solution (range $0.0008-0.06 \mathrm{mmol} / \mathrm{mL} \quad \mathrm{Ho}$ ). Therefore, a stock solution was prepared of $0.06 \mathrm{mmol} /$ $\mathrm{mL} \mathrm{Ho}$, mixed for $5 \mathrm{~min}$, and diluted by adding demineralised water. The concentration of the solutions was corrected for the mass percentage of $\mathrm{Ho}$ of the $\mathrm{HoCl}_{3}$ $(43.47 \%)$

Two batches of $1,200 \mathrm{mg}{ }^{165} \mathrm{HoMS}$, mass percentage $17.6 \%$ and $18.7 \%$ [14], were suspended in the injection solution containing $116 \mathrm{mmol}$ phosphate ( $\mathrm{pH}$ 7.2)-buffered saline with polyoxyethylene-polyoxypropylene block copolymer (Pluronic F-68, Sigma-Aldrich Chemie N.V., Zwijndrecht, The Netherlands) $2 \%$ weight per volume solution, and then diluted to ten concentrations (range $0.25-20.0 \mathrm{mg} / \mathrm{mL}^{165} \mathrm{HoMS}$ or $0.0016-0.12 \mathrm{mmol} / \mathrm{mL}$ Ho) of ${ }^{165}$ HoMS. The ${ }^{165}$ HoMS solutions were subsequently mixed 1:1 with a 2\% agar (MP Agar, Roche Diagnostics, Almere, The Netherlands) solution to prevent settling due to the weight of these Ho microspheres $(1.4 \mathrm{~g} / \mathrm{mL})$. Therefore, the agar powder was dissolved in sterile water (Versylene, Fresenius Kabi, B.V., Huis Ter Heide, The Netherlands) and heated to $90{ }^{\circ} \mathrm{C}$ for $10 \mathrm{~min}$, resulting in a transparent fluid. Subsequently, a $5 \mathrm{~mL}$ Eppendorf tube was filled with $5 \mathrm{~mL}$ of the homogeneously distributed Ho microspheres in agar solution in a series $(n=10)$ with a concentration ranging from 0.125 to $10.0 \mathrm{mg} / \mathrm{mL}$ Ho. Once cooled to room temperature in approximately $5 \mathrm{~min}$ of continuous rotation to prevent settling, the agar became solid.

\section{Ex vivo and in vivo administration of ${ }^{166} \mathrm{HoMS}$}

Radioactive ${ }^{166} \mathrm{Ho}-\mathrm{MS}$ with a known specific activity $(\mathrm{Bq} / \mathrm{mg})$ were suspended in a solution of $2 \%$ weight by volume Pluronic ${ }^{\oplus}$ F-68 (Sigma-Aldrich Chemie N.V., Zwijndrecht, The Netherlands) in a $116-\mathrm{mmol}$ phosphate ( $\mathrm{pH}$ 7.2) buffer by gentle agitation and repeatedly drawing up and down in a $1 \mathrm{~mL}$ Luer-lock syringe (Becton Dickinson S.A., Madrid, Spain). The injections of the ${ }^{166}$ HoMS were performed with a $1-\mathrm{mL}$ Luer-lock syringe 
through a $21 \mathrm{G} \times 1 \frac{112}{2} "(0.8 \times 40 \mathrm{~mm})$ hypodermic needle (Becton Dickinson S.A., Madrid, Spain). The activity of the ${ }^{166} \mathrm{HoMS}$ inside the syringes was measured using a calibrated dose calibrator (VDC-404; Veenstra Instruments, Joure, The Netherlands). The injection procedures were performed by the intratumoural Ho research team. Ex vivo and in vivo (laboratory animals) injections were performed by $\mathrm{RCB}, \mathrm{FN}$, and $\mathrm{BvN}$. In human patients, injections were performed under ultrasound guidance by ML (nuclear physician) assisted by other members of the team.

\section{Ex vivo CT quantification of ${ }^{166} \mathrm{Ho}-\mathrm{MS}$}

The feasibility of CT Ho quantification was evaluated in five samples of ex vivo chicken muscle tissue. Syringes with approximately $0.2 \mathrm{~mL}$ of ${ }^{166} \mathrm{Ho}-\mathrm{MS}$ suspension with increasing activity ranging from 15 to $81 \mathrm{MBq}$ (corresponding to 3.4 to $18.4 \mathrm{mg} \mathrm{Ho}$ ) were injected into the tissue samples. The actually injected amount of Ho (mg) was determined by the injected activity. To determine the injected activity, the syringes (before and after injection), the gauze with potential injection channel leakage, and the tissue sample were measured in the dose calibrator. Based on these measurements, the known specific activity of the ${ }^{166} \mathrm{Ho}-\mathrm{MS}$ and the weight and mass percentage of the ${ }^{166} \mathrm{Ho}-\mathrm{MS}$ as well as the injected amount (mg) of Ho was calculated.

\section{Laboratory animals}

All experiments were performed in agreement with "The Netherlands Experiments on Animals Act" (1977) and "The European Convention for the Protection of Vertebrate Animals used for Experimental Purposes" (Strasbourg, 18.III.1986). Approval was obtained from the Utrecht University Animal Experiments Committee (DEC 2011.III.08.080).

The VX-2 tumour model in New Zealand white rabbits was previously described [15]. In short, in one animal, the donor rabbit, a tumour was implanted by injection of a suspension of approximately $4.0 \times 10^{7} \mathrm{VX}$ 2 carcinoma cells subcutaneously into both flanks. Single tumours were induced in each of five rabbits by harvesting the tumour from the donor rabbit. A subcutaneous injection of $3 \pm 1 \mathrm{~mm}^{3}$ viable fragments of VX-2 carcinoma with $0.1-0.3 \mathrm{~mL}$ phosphate-buffered saline was performed into the flank of five adult female New Zealand White rabbits weighing $3-4 \mathrm{~kg}$. All tumour implantations and treatments were performed under analgesia with carprofen $4 \mathrm{mg} / \mathrm{kg}$. During the animal experiments, sedation and analgesia were achieved with a mixture of $0.125 \mathrm{mg} / \mathrm{kg}$ dexdomitor and $15 \mathrm{mg} / \mathrm{kg}$ ketamine.

After the intratumoural injection of $0.2 \mathrm{~mL}$ of ${ }^{166} \mathrm{Ho}-$ MS suspensions in five rabbits, a CT scan was performed according to the clinical protocol described below. Only in rabbit number 5, a higher amount of activity $(57.9 \mathrm{MBq})$ was injected for comparison to quantitative SPECT imaging and depositions outside the tumour. CT and SPECT data were compared to the injected mg Ho, which was determined by the injected activity as described above.

\section{Patients}

Human patients previously treated with direct intratumoural injections of ${ }^{166} \mathrm{Ho}$-MS were analysed to provide an example of clinical CT quantification method. Between 2015 and 2017, four patients with head and neck cancer were referred by their head and neck oncologist. Three patients were treated in a palliative setting. If no other palliative treatment options were available, and nonetheless a strong wish for treatment existed, patients were amenable for direct intratumoural injections of ${ }^{166} \mathrm{Ho}-\mathrm{MS}$, with the aim of improving the patients' quality of life. One patient was part of a prospective clinical pilot study (NCT02975739) [8]. All patients provided informed consent before treatment. Immediately after two to four ultrasound-guided intratumoural injections, containing a total of $100 \mathrm{mg}$ of ${ }^{166} \mathrm{Ho}-\mathrm{MS}$, a SPECT, a highdose CT, and a planar scintigraphy of thorax and abdomen (imaging time 300) were performed. This retrospective analysis of patients treated in a palliative setting was approved by the medical ethical committee of the University Medical Center Utrecht. Some study subjects or cohorts have been previously reported [8].

\section{CT and SPECT}

All CT and SPECT imaging was performed using a Symbia T16 SPECT/CT system (Siemens, Erlangen, Germany) that combines a dual-headed gamma camera with a 16-slice CT system. The acquisition parameters were identical to a diagnostic high-dose CT scan of the head and neck region in the clinical setting: tube voltage $110 \mathrm{kVp}$, effective tube current $225 \mathrm{mAs}$; detector configuration $16 \times 0.6 \mathrm{~mm}$; rotation time $0.6 \mathrm{~s}$; helical scan mode; pitch 1.0. Images were reconstructed with a 1.5$\mathrm{mm}$ slice thickness with a $0.7 \mathrm{~mm}$ increment (voxels size $0.56 \times 0.56 \times 0.7 \mathrm{~mm}$ ) and a B31s medium smooth reconstruction kernel.

Medium-energy low-penetration collimators were used on both SPECT cameras. Energy windows were set at $80.6 \mathrm{keV}$ (15\% window width) for the ${ }^{166}$ Ho photopeak. A total of 120 projections of $30 \mathrm{~s}$ were acquired in a $360^{\circ}$ noncircular orbit. Quantitative image data were reconstructed to a $128^{3}$ matrix with an isotropic voxel size of $4.8 \mathrm{~mm}^{3}$. The reconstructions were performed using previously validated Monte-Carlo-based reconstruction software $[2,16]$ using an ordered subsets expectation maximisation algorithm (10 iterations with 8 subsets) and a quantitatively correct forward model, resulting in 
an absolute quantitative three-dimensional activity distribution in $\mathrm{MBq} /$ voxel [2]. Based on the recovered activity and the specific activity of the microspheres, the absolute amount of Ho (mg) was calculated.

\section{Data analysis}

CT data were analysed with ImageJ version $1.50 \mathrm{~b}(\mathrm{NIH}$, Bethesda, USA). In the phantom of both $\mathrm{HoCl}_{3}$ and HoMS, a circular region of interest (ROI) with a $10-\mathrm{mm}$ diameter was drawn in the centre of the 5-mL Eppendorf tube. This ROI was applied over 30 slices to create a volume of interest of $1.6 \mathrm{~cm}^{3}$. Subsequently, HU value of this VOI (mean \pm standard deviation [SD]) was calculated. A scatterplot of the observed $\mathrm{HU}$ values against the calculated concentration values was made to obtain a calibration curve.

In the chicken muscle tissue experiments, an VOI was drawn in an area without microspheres. From this VOI, the mean $\pm \mathrm{SD}$ and maximum $\mathrm{HU}$ values were obtained. In the animals and patients, the tumour volume was manually segmented on CT images by one of the investigators (RCB). Based on the literature, it was assumed that all tumour voxels had a HUvalue between -50 and 100 [17] and that all voxels with a HU > 100 contained Ho microspheres. The amount of Ho was calculated using the following strategy:

1. All voxels with $\mathrm{HU}>100$ were selected and divided by the $\mathrm{HU} /$ concentration calibration curve, to obtain a concentration of $\mathrm{mg} / \mathrm{ml} / \mathrm{voxel}$;

2. This concentration was multiplied by the voxel volume $\left(0.22 \mathrm{~mm}^{3}\right)$ to calculate the absolute amount of Ho per voxel;

3. The total sum of these voxels resulted in the total amount of Ho in milligrams.

Continuous data were presented as mean \pm SD deviation if normally distributed and as the median and range if skewed (Shapiro-Wilk test). A Pearson correlation coefficient between the dose calibrator, CT-, and SPECTquantification was calculated if normally distributed, with Spearman rank-order correlation if skewed. Agreement between the measurements was presented as the recovered percentage on SPECT or CT compared to the dose calibrator or SPECT. SPSS software (SPSS for Windows, version 22.0; SPSS Inc., Armonk, USA) was used for all analysis.

\section{Results}

\section{Phantom calibration}

The Ho concentration of the ${ }^{165} \mathrm{Ho}-\mathrm{MS}$ solutions and the $\mathrm{HoCl}_{3}$ solution ranged from 0 to approximately 10 $\mathrm{mg} / \mathrm{mL}$. Solutions with increasing Ho concentration resulted in increased $\mathrm{HU}$ values from around zero $\mathrm{HU}$ up to approximately $370 \mathrm{HU}$ (Table 1). The slope of the regression of the three Ho dilution series was 36.9, 37.0, and $37.2 \mathrm{HU}$ per $\mathrm{mg} / \mathrm{mL}$ of Ho atoms, for the $18.7 \%$ and $17.6 \%{ }^{165} \mathrm{Ho}-\mathrm{MS}$ solution and the $\mathrm{HoCl}_{3}$ solution, respectively (Fig. 1c). The linear regression between $\mathrm{Ho}$ in $\mathrm{mg} / \mathrm{mL}$ and the HU showed a good fit (least squares $R^{2}$ $>0.99$ ) for all series (Fig. 1), without a significant difference between the three lines.

The feasibility of CT quantification was tested in ex vivo chicken muscle tissue. Based on the literature, a threshold of $100 \mathrm{HU}$ was adopted [17]. The VOIs of the chicken muscle tissue without Ho showed a mean HU of $71.2 \pm 7.1$ with a maximum observed HU value of 96 . The chosen cutoff value of $>100 \mathrm{HU}$ was more than the maximum HU value observed and more than three times the SD of unenhanced chicken muscle tissue.

The validated ${ }^{166} \mathrm{Ho}-\mathrm{SPECT}$ was tested with $5-\mathrm{mL}$ Eppendorf tubes filled with known activities (dose calibrator) and recovered from $99.5 \pm 1.4 \%$ (mean \pm SD) of the activity. SPECT recovered $94.6 \pm 4.9 \%$ (mean \pm SD) of the injected activity in the tissue (Table 2). There was a strong positive correlation between the injected activity and the activity recovered by SPECT ( $n=5, r=0.99, p$ $<0.001$ ), with a recovered percentage ranging from 90.6 and $101.3 \%$.

After injection, the total volume of voxels with a $>100$ $\mathrm{HU}$ varied from 0.3 to $1.5 \mathrm{~cm}^{3}$. A positive correlation was observed between the volume and the amount of injected Ho $(n=5, r=0.90, p=0.043)$. Using the simple method described above, $81.5 \pm 6.7 \%$ (mean $\pm \mathrm{SD}$ ) of the Ho was recovered using CT (Table 2).

\section{Laboratory animals}

Nineteen days after VX-2-tumour implantation, five tumours reached a diameter of approximately $20 \mathrm{~mm}$ in the rabbits (Table 3). Before the injection of ${ }^{166} \mathrm{Ho}-\mathrm{MS}$, the tumour was segmented on CT (Fig. 2a). The mean tumour volume was $4.8 \pm 1.9 \mathrm{~cm}^{3}\left(\right.$ range $\left.3.2-7.2 \mathrm{~cm}^{3}\right)$. The mean tumour $\mathrm{HU}$ was $31.6 \pm 14.3$ with a maximum of $98 \mathrm{HU}$.

After the injection of ${ }^{166} \mathrm{Ho}-\mathrm{MS}$, areas with high attenuation were seen inside the tumour caused by the accumulation of microspheres (Fig. 2b). Analysis of the observed $\mathrm{HU}$ values in the VOI before and after injection shows a right-skewed distribution due to voxels containing Ho. Accidental injection of air into rabbit 2 and 5 resulted in voxels with highly negative $\mathrm{HU}$ (e.g., $-722 \mathrm{HU}$ ) observed as radiolucent area (Fig. 2c) and a left-skewed distribution (Fig. 2d). The volume of voxels showing $>100 \mathrm{HU}$ values ranged $0.1-0.5 \mathrm{~cm}^{3}$ or $3-9 \%$ of the total tumour volume.

In these rabbits, $76.0 \pm 15.4 \%$ (range $59.9-100.0 \%$ ) of the administered Ho according to the dose calibrator measurements was recovered on CT (Table 3). A positive correlation between the injected amount and the recovered amount on CT was found $(n=5, r=0.97, p=$ 
Table 1 Phantom Ho quantification

\begin{tabular}{|c|c|c|c|c|c|}
\hline \multicolumn{2}{|c|}{ Ho microspheres (18.7\%) in agar } & \multicolumn{2}{|c|}{ Ho microspheres (17.6\%) in agar } & \multicolumn{2}{|c|}{ Ho chloride (43.47\%) in water } \\
\hline Ho & $\mathrm{HU}$ & $\mathrm{Ho}$ & $\mathrm{HU}$ & $\mathrm{Ho}$ & $\mathrm{HU}$ \\
\hline $\mathrm{mg} / \mathrm{mL}$ & Mean \pm SD & $\mathrm{mg} / \mathrm{mL}$ & Mean \pm SD & $\mathrm{mg} / \mathrm{mL}$ & Mean \pm SD \\
\hline 0.00 & $-2.6 \pm 8.0$ & 0.00 & $10.1 \pm 7.5$ & 0.00 & $1.9 \pm 6.6$ \\
\hline 0.16 & $-0.7 \pm 9.9$ & 0.14 & $12.5 \pm 7.1$ & 0.13 & $3.4 \pm 6.5$ \\
\hline 0.25 & $2.2 \pm 6.9$ & 0.26 & $15.3 \pm 6.1$ & 0.25 & $9.5 \pm 5.8$ \\
\hline 0.53 & $20.8 \pm 6.8$ & 0.52 & $20.9 \pm 7.6$ & 0.50 & $18.4 \pm 7.1$ \\
\hline 1.00 & $37.3 \pm 7.1$ & 1.05 & $30.3 \pm 8.8$ & 1.00 & $34.1 \pm 6.9$ \\
\hline 2.00 & $65.9 \pm 7.1$ & 2.10 & $79.9 \pm 7.2$ & 2.00 & $72.2 \pm 6.3$ \\
\hline 4.02 & $148.2 \pm 8.2$ & 4.19 & $158.4 \pm 8.1$ & 4.00 & $145.7 \pm 6.9$ \\
\hline 5.99 & $215.3 \pm 13.4$ & 6.28 & $239.7 \pm 9.5$ & 6.01 & $223.4 \pm 7.2$ \\
\hline 8.01 & $283.9 \pm 16.8$ & 8.37 & $321.4 \pm 9.4$ & 8.01 & $301.1 \pm 8.2$ \\
\hline 9.99 & $372.4 \pm 14.1$ & 10.47 & $383.1 \pm 14.8$ & 10.01 & $370.0 \pm 10.5$ \\
\hline
\end{tabular}

Observed $\mathrm{HU}$ for the 5 - $\mathrm{mL}$ Eppendorf tubes with a concentration ranging from approximately 0 to $10 \mathrm{mg} / \mathrm{mL}{ }^{166} \mathrm{Ho}$-microspheres (18.7, $\left.17.6 \%\right)$ and Ho chloride (43.47\%) in styrofoam (as seen in Fig. 1) measured on a Siemens Symbia T16

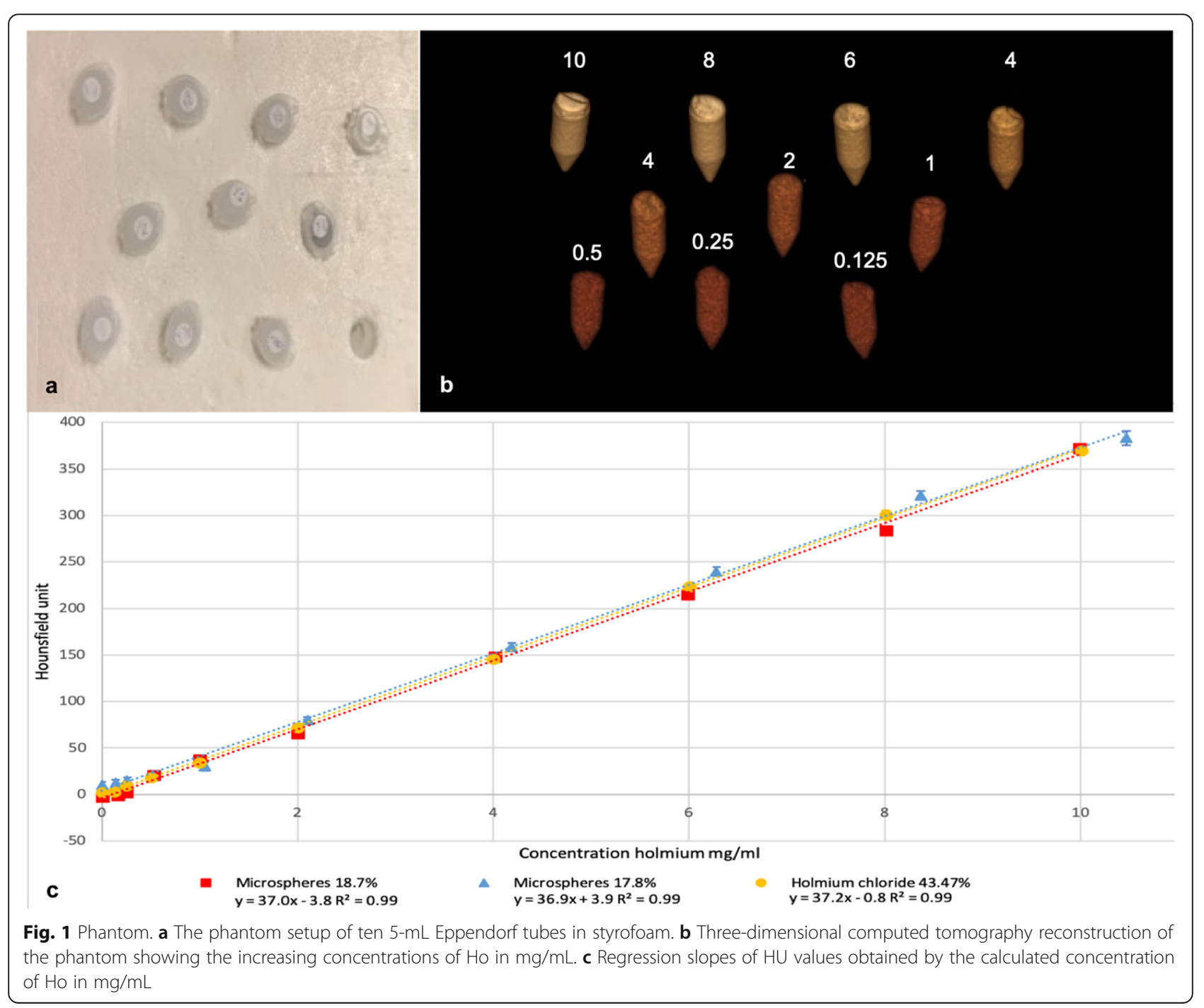


Table 2 Ex vivo Ho recovery by single-photon emission computed tomography (SPECT) and computed tomography (CT)

\begin{tabular}{|c|c|c|c|c|c|c|}
\hline & \multicolumn{2}{|c|}{ Injected Ho } & \multicolumn{2}{|c|}{ SPECT recovery } & \multicolumn{2}{|c|}{$\mathrm{CT}$ recovery } \\
\hline & $\mathrm{MBq}$ & $\mathrm{mg}$ & $\mathrm{MBq}$ & $\%$ & $\mathrm{mg}$ & $\%$ \\
\hline Tissue 1 & 81.1 & 18.0 & 75.9 & 93.6 & 16.1 & 89.8 \\
\hline Tissue 2 & 73.6 & 16.3 & 67.6 & 91.9 & 13.2 & 81.0 \\
\hline Tissue 3 & 40.3 & 8.9 & 36.5 & 90.6 & 7.3 & 81.7 \\
\hline Tissue 4 & 24.4 & 5.4 & 23.1 & 94.7 & 4.4 & 81.5 \\
\hline Tissue 5 & 15.4 & 3.4 & 15.6 & 101.3 & 2.5 & 73.8 \\
\hline
\end{tabular}

Two 5-mL Eppendorf tubes filled with activity were used for SPECT calibration. Five samples of chicken muscle tissue were injected with radioactive microspheres ranging from 15.4 to $81.1 \mathrm{MBq}$ with the corresponding amount of $\mathrm{mg} \mathrm{Ho}$. Based on the dose calibrator measurements, SPECT, and CT imaging recovered $90.6-101.3 \%$ and $73.8-89.9 \%$, respectively

0.027 ) with a recovered percentage ranging from $59.9 \%$ to $100 \%$. The SPECT analysis of rabbit 5, injected with $57.9 \mathrm{MBq}$ of ${ }^{166} \mathrm{Ho}-\mathrm{MS}$, showed a clear hotspot at the tumour location. Depositions of activity were not seen outside the tumour (e.g., in the kidney or lung). The recovered activity on SPECT was $54.3 \mathrm{MBq}$, equal to $93.7 \%$ of the injected activity.

\section{Patients}

Four patients were treated with intratumoural ${ }^{166} \mathrm{Ho}-$ MS injections (Table 4). One patient did not tolerate SPECT imaging due to orthopnoea and was not included in the analysis. Patient 2 was treated on both sides of the neck. The tumour volume of patients ranged from 3.9 to $44.6 \mathrm{~cm}^{3}$ (Table 4 ). According to the dose calibrator, the injected activity ranged from 17.6 to $366.7 \mathrm{MBq}$, corresponding with an absorbed dose of 111 to $165 \mathrm{~Gy}$. The total volume of voxels with $>100 \mathrm{HU}$ values ranged from 0.5 to $2.7 \mathrm{~cm}^{3}$ or $6.1 \%$ to $23.1 \%$ of the tumour volume.

In patient number 1 , ultrasound guidance showed precipitation of microspheres after injection indicating liquefaction of the tumour centre probably due to tumour necrosis. CT provided a clear distribution and accumulation of the ${ }^{166} \mathrm{Ho}-\mathrm{MS}$ after injection as shown in Fig. 3. Compared to SPECT and MRI, the deposition of high concentrations of Ho was more accurately depicted on CT. CT could discriminate two separate distributions which merged on SPECT and MRI and was able to quantify higher concentrations than MRI (Fig. 4). The injected ${ }^{166}$ HoMS resulted in local cell death microscopically (Fig. 4).

The CT-based quantification method recovered $88.8 \%$ of the injected activity in patient number 1 , while $84.3 \%$ was recovered by SPECT (Table 4). Recovery of injected activity was much lower for patients number 2 and number 3, probably because of unperceived leakage of activity after intratumoural injection. The CT recovery in all patients corresponded well with SPECT recovery ( $\rho=1.0, n=4, p=0.045)$, and CT recovered from 88.7 to $105.3 \%$ of the intratumoural activity recovered on SPECT (Table 4).

\section{Discussion}

This is the first report investigating the clinical quantification of ${ }^{166}$ Ho-MS using CT. CT quantification may be of additional value to the currently used imaging modalities such as MRI and SPECT because of its superior spatial resolution, the opportunity to perform real-time imaging, lower costs, and widespread availability. CT scanning is especially suitable for rapid imaging feedback of the ${ }^{166} \mathrm{HoMS}$ distribution and to visualise potentially skipped areas during treatment. Based on the CT imaging during treatment, the distribution of ${ }^{166} \mathrm{Ho}-\mathrm{MS}$ can be optimised either by injecting additional microspheres if a lethal absorbed dose is not reached or by discontinuing further administration if a lethal dose is met or if undesired spread of ${ }^{166} \mathrm{Ho}-\mathrm{MS}$ is observed. After treatment, a combined SPECT/CT examination,

Table 3 In vivo Ho recovery in subcutaneous VX-2 tumour-bearing rabbits by single-photon emission computed tomography (SPECT) and computed tomography (CT)

\begin{tabular}{|c|c|c|c|c|c|c|c|c|c|}
\hline \multirow[t]{2}{*}{ Rabbit } & \multicolumn{2}{|c|}{ Injected Ho } & \multirow{2}{*}{$\begin{array}{l}\text { Tumour volume } \\
\mathrm{cm}^{3}\end{array}$} & \multicolumn{2}{|c|}{ Volume of voxels with $\mathrm{HU}>100$} & \multicolumn{2}{|c|}{ CT recovery } & \multicolumn{2}{|c|}{ SPECT recovery } \\
\hline & $\overline{\mathrm{MBq}}$ & $\overline{\mathrm{mg}}$ & & $\overline{\mathrm{cm}^{3}}$ & $\%$ & $\overline{\mathrm{mg}}$ & $\%$ & $\overline{\mathrm{MBq}}$ & $\%$ \\
\hline 1 & 0.10 & 3.6 & 6.6 & 0.5 & 6.9 & 2.8 & 77.7 & NP & \\
\hline 2 & 0.07 & 2.2 & 6.0 & 0.2 & 3.5 & 1.3 & $59.9^{*}$ & NP & \\
\hline 3 & 0.04 & 1.4 & 7.2 & 0.2 & 3.2 & 1.1 & 76.9 & NP & \\
\hline 4 & 0.01 & 0.4 & 3.2 & 0.1 & 2.5 & 0.4 & 100.0 & NP & \\
\hline 5 & 57.9 & 2.9 & 3.4 & 0.3 & 9.1 & 1.9 & $65.4^{*}$ & 54.3 & $93.8 \%$ \\
\hline
\end{tabular}

Five rabbits with subcutaneous VX-2 tumours were injected with decayed or radioactive microspheres with the corresponding amounts of Ho. The tumour volume ranged from 3.2 to $7.2 \mathrm{~cm}^{3}$, based on the $\mathrm{HU}<100$ threshold while $0.1-0.5 \mathrm{~cm}^{3}$ or $2.5-9.1 \%$ of the tumour volume was filled with holmium after treatment. Ho recovery by CT ranged from 59.9 to $100.0 \%(n=5)$, recovery by SPECT was $93.8 \%(n=1)$ 


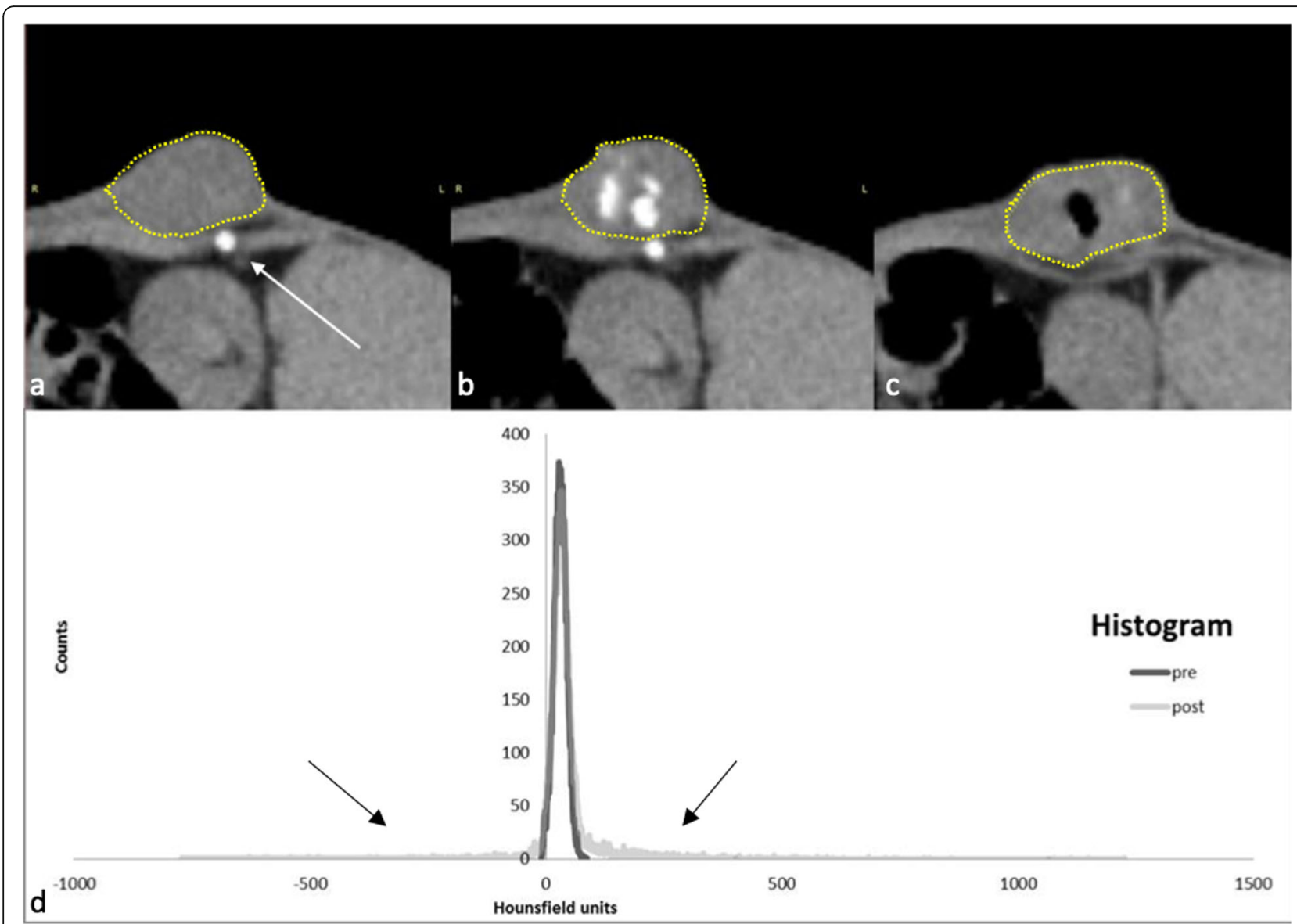

Fig. 2 Ho quantification in a subcutaneous VX-2 bearing rabbit. Rabbit 2. a Tumour before injection. The tumour is segmented with a yellow dotted line. The white arrow shows a rib. The rib is also visible in $\mathbf{b}$. $\mathbf{b}$ Tumour after injection with accumulations of Ho microspheres, visible as white dots, indicated with white arrows. c A different axial slice shows the effect of inadvertent injection of air (black void inside the tumour). $\mathbf{d}$ Histogram of $\mathrm{HU}$ values of the entire tumour before and after injection of ${ }^{166} \mathrm{Ho}$ microspheres. The large negative (left of peak) and positive tail (right of peak) are caused by a relatively small number of voxels with injected air or Ho, respectively

which allows for both imaging of ${ }^{166} \mathrm{Ho}-\mathrm{MS}$ distribution and recovery of possible leakage outside the treated region, should be performed.

Holmium has a high CT attenuation coefficient due to its high electron density (atomic number 67) and a K-edge $(56 \mathrm{keV})$ close to the mean energy of the photons emitted in CT $(63 \mathrm{keV}$ at a tube voltage of $120 \mathrm{kV})$ [19]. It has previously been shown that lanthanides like Ho have up to $50 \%$ higher $\mathrm{x}$-ray attenuation than iodine in CT [20]. The phantoms with $\mathrm{HoCl}_{3}$ and two batches of ${ }^{166} \mathrm{Ho}-\mathrm{MS}$ showed a comparable linear slope of $36.9-37.2 \mathrm{HU} / \mathrm{mg} / \mathrm{mL}$ of Ho with a good linear fit suggesting that this regression can be used for the entire range of concentrations.

Table 4 Ho recovery in patients single-photon emission computed tomography (SPECT) and computed tomography (CT)

\begin{tabular}{|c|c|c|c|c|c|c|c|c|c|c|c|}
\hline \multirow[t]{2}{*}{ Patient } & \multirow{2}{*}{$\begin{array}{l}\text { Tumour volume } \\
\mathrm{cm}^{3}\end{array}$} & \multicolumn{2}{|c|}{ Injected Ho } & \multicolumn{2}{|c|}{ SPECT recovery } & \multicolumn{2}{|c|}{ CT recovery } & \multicolumn{4}{|c|}{ Volume of voxels with $\mathrm{HU}>100$} \\
\hline & & $\overline{\mathrm{MBq}}$ & $\overline{\mathrm{mg}}$ & $\overline{\mathrm{MBq}}$ & $\%$ & $\overline{\mathrm{mg}}$ & $\%$ & $\overline{\mathrm{cm}^{3}}$ & & $\%$ & \\
\hline 1 & 44.6 & 366.7 & 36.5 & 309.2 & 84.3 & 32.4 & 88.8 & & 2.7 & & 6.1 \\
\hline 2 left & 5.6 & 53.9 & 13.7 & 9.6 & 17.8 & 2.3 & 16.5 & & 0.5 & & 8.0 \\
\hline 2 right & 6.1 & 63.8 & 16.2 & 16.9 & 26.5 & 3.8 & 23.5 & & 0.6 & & 9.3 \\
\hline 3 & 3.9 & 17.6 & 3.1 & 8.5 & 48.3 & 1.5 & 48.6 & & 0.9 & & 23.1 \\
\hline
\end{tabular}

Three patients with recurrent head and neck cancer were treated with radioactive ${ }^{166} \mathrm{Ho}$-microspheres and underwent SPECT/CT imaging. Patient 2 was treated on both sides of the neck. Base on the injected activity, the corresponding amount of $\mathrm{mg}$ Ho was calculated. Injected activity compared to SPECT recovery was $17.8-84.3 \%$. CT recovery was in line with SPECT imaging ranging from 16.5 to $88.8 \%$. Tumour volume was $3.9-44.6 \mathrm{~cm}^{3}$ based on the $>100 \mathrm{HU}$ threshold; from 6.1 to $23.1 \%$ of tumour volume was filled with ${ }^{166} \mathrm{Ho}$-microspheres 


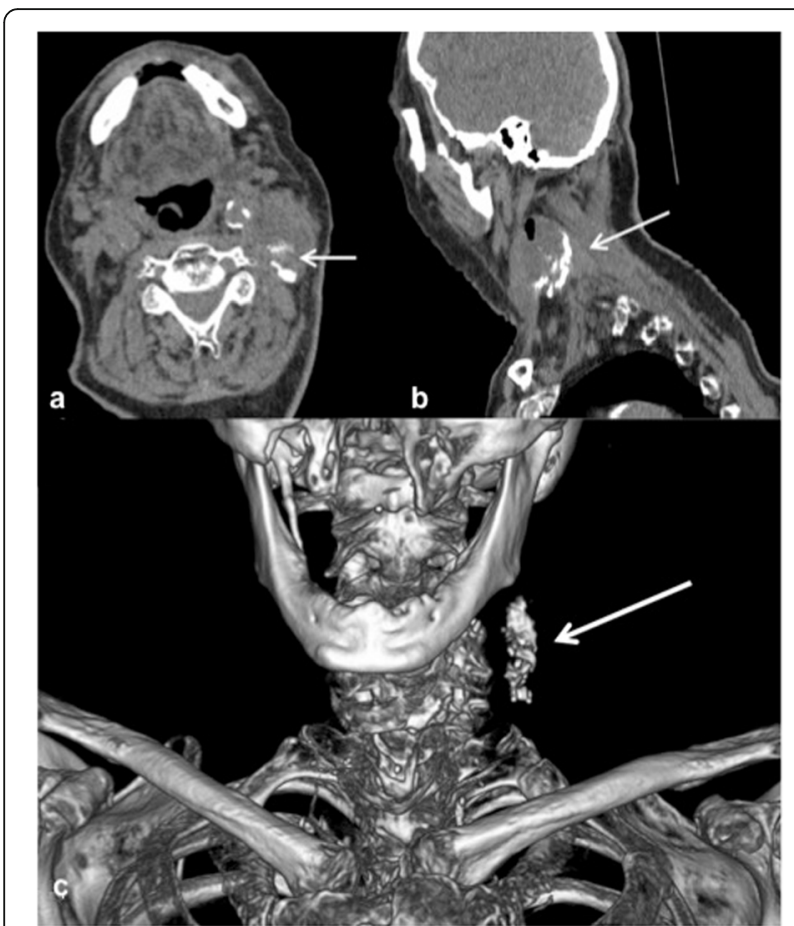

Fig. 3 Computed tomography (CT) images of patient number 1 . Axial, sagittal, and three-dimensional CT reconstructions of patient number 1 with a large necrotic tumour on the left neck side. During injection, the holmium microspheres were clearly visible on

ultrasound as a cloud in the necrotic fluid and did precipitate after some minutes at the bottom of the tumour. The dorsal and caudal accumulation of ${ }^{166} \mathrm{Ho}$ microspheres in the tumour is also well visible in the three images obtained in supine position (arrows in $\mathbf{a}$, b, and $\mathbf{c}$ )

The feasibility of CT-based quantification was initially tested on ex vivo muscle tissue. A threshold of $100 \mathrm{HU}$ was used to derive quantification of ${ }^{166} \mathrm{Ho}-\mathrm{MS}$. This threshold of $100 \mathrm{HU}$ was selected based on the literature [17] and on the current data in this article. The maximum $\mathrm{HU}$ in all ex vivo muscle tissues was below 100. In addition, this was more than three times the SD of muscle tissue and segmented VX-2 tumours in rabbits. However, Ho recovery up to $2.7 \mathrm{mg} / \mathrm{mL}$ (100 HU/37.0 $\mathrm{HU} / \mathrm{mg} / \mathrm{mL} \mathrm{Ho}$ ) may be difficult. A lower threshold would lead to the recovery of more Ho but would also result in increased noise, while a higher threshold would result in a higher specificity at the cost of sensitivity. The used $>100 \mathrm{HU}$ threshold remains arguable. Nevertheless, using this simple quantification method, 59.9$100.0 \%$ of the injected microspheres were recovered.

There are several advantages of CT-based Ho quantification as compared to the current SPECT imaging. First, a more accurate assessment of the intratumoural distribution of ${ }^{166} \mathrm{Ho}-\mathrm{MS}$ is possible because of a better spatial resolution of $\mathrm{CT}$. The fact that the $\beta$ radiation of ${ }^{166} \mathrm{Ho}$ has an average penetration range of only a few millimetres while $90 \%$ of the dose is absorbed whithin $2.1 \mathrm{~mm}$ [21] stresses the importance of using highresolution imaging. Additional injections, based on the current microsphere distribution, could provide a more homogeneously absorbed dose and subsequently a more favourable treatment outcome. CT imaging can provide such high-resolution imaging in a few seconds, compared with $45 \mathrm{~min}$ for SPECT, thus enabling the realtime use of CT for feedback for subsequent injections. Furthermore, in case of intratumoural treatment, relatively high radiation doses (200-800 Gy) [6] are used with higher concentrations of microspheres, resulting in non-quantifiable artefacts on MRI.

The standard of reference for the quantification of ${ }^{166}$ Ho-MS remains SPECT. First, because of the superior sensitivity at low amounts of activity compared with CT as the Ho CT detection limit, under optimal circumstances in a homogeneous solution $(0.057 \mathrm{mg} / \mathrm{mL})$ is about one hundred times higher than that of SPECT $(0.00054 \mathrm{mg} / \mathrm{mL})$ [22]. Especially in the case of accidental extratumoural deposition, voxels with low Ho concentrations may be not discriminated from normal tissues on CT. Furthermore, SPECT directly quantifies activity, while CT detects only Ho as a metal in terms of electronic density, which is indirectly used to quantify activity by multiplying the amount of microspheres with the known specific activity [22]. On the other hand, SPECT has a significantly lower spatial resolution resulting in a limited sensitivity for intratumoural inhomogeneities and insufficient detail of the actual dose distribution within the treated tumour.

The method presented in this work has several limitations. First, in this feasibility study, there was a limited number of images available for analysis. The Pearson correlation showed a strong correlation, and the recovered percentage was within acceptable range. However, more advanced statistical analyses to assess the absolute agreement were not performed due to the small sample size. Second, the CT acquisition protocols, including tube current, dose, image reconstruction kernels, and equipment, all may have had an impact on CT-based quantification and could be further optimised. Third, the $>100 \mathrm{HU}$ threshold may not be the best threshold in each individual patient and tissue. In addition, tissue with high density, like bone, calcifications, or foreign bodies such as metallic artefacts and beam-hardening artefact could result in quantification errors on CT. In the presented patients, scatter artefacts were present. However, the effect was minimal at the tumour locations that were injected.

A more specific and sensitive method to determine the content of Ho per voxel is desired. Material decomposition with dual-energy and photon-counting CT may provide more specific and accurate quantification and is 


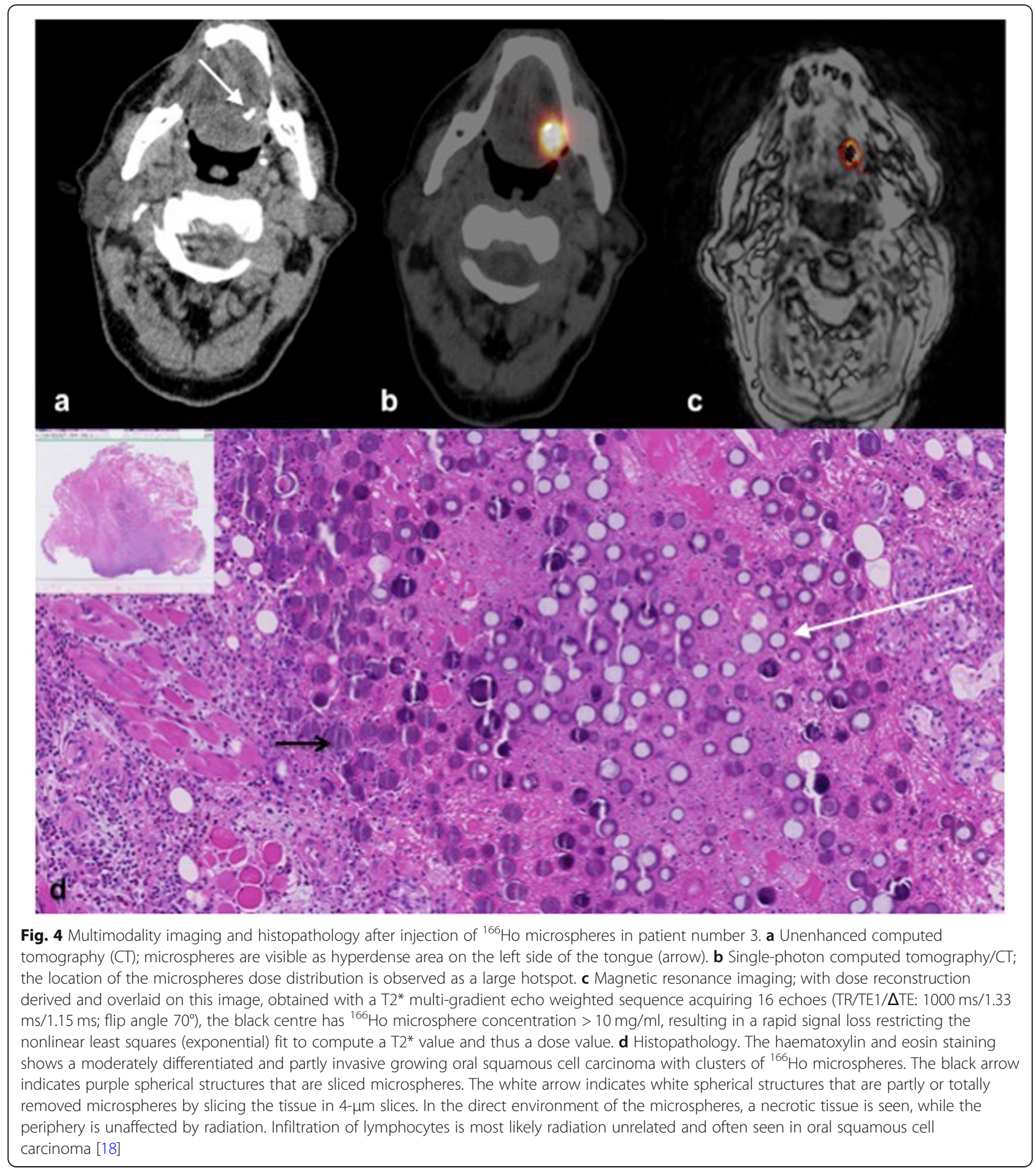

currently used for iodine CT-based quantification [19, 23]. Combining the imaging opportunities for treatment planning and evaluation with accurate image-guided and robotic-assisted ${ }^{166} \mathrm{Ho}-\mathrm{MS}$ administration [24, 25] may result in personalised "dose painting" in which the planned dose is injected on the desired location within the tumour. This combination of imaging and robotic administration may ultimately change the treatment paradigm in oncology, particularly for single tumours that may be reached by a needle, including head-neck cancer, brain tumours, and pancreatic tumours that are still associated with a poor prognosis.

In conclusion, we showed the metal $\mathrm{Ho}$ in radioactive ${ }^{166} \mathrm{Ho}$-MS for local treatment of tumours can quantified on 
CT and seems to be a true multimodality-imaging isotope with quantitative imaging capabilities using SPECT, MRI, and CT. CT provides high-resolution imaging of intratumoural ${ }^{166} \mathrm{HoMS}$ distribution and enables quantification of high local ${ }^{166}$ HoMS concentrations. CT may especially be suitable for an image-guided treatment approach, providing rapid intraprocedural imaging feedback of the ${ }^{166}$ HoMS distribution, directing subsequent injections in possible skipped areas. Such a "dose painting" approach may greatly optimise tumour dose coverage and subsequent clinical outcome.

\begin{abstract}
Abbreviations
${ }^{166} \mathrm{Ho}-\mathrm{MS}$ : Radioactive holmium-166 $\left({ }^{166} \mathrm{Ho}\right)$-loaded (poly L-lactic acid) microspheres; 3D: Three-dimensional; CT: Computed tomography; MRI: Magnetic resonance imaging; ROI: Region of interest; SD: Standard deviation; SPECT: Single-photon emission computed tomography; VOI: Volume of interest

\section{Acknowledgements}

QuiremSpheres ${ }^{\circledast}$ were provided by Quirem Medical BV.

\section{Authors' contributions}

$\mathrm{RCB}, \mathrm{SvN}, \mathrm{AB}$, and FN made substantial contributions to the conception and design of the work, in performing of the experiments in the pre-clinical setting, and in the interpretation of the data. RvE, AR, and ML selected the potential suitable patient and performed the treatment in the patients. RB and $\mathrm{HdJ}$ made substantial contributions in obtaining and in the analysis of the SPECT and CT data. All authors made substantial contribution to the writing of the manuscript and read and approved the final manuscript.
\end{abstract}

\section{Funding}

This research was financially supported by the Dutch Cancer Foundation (KWF: grant number 2014-7075). The funding body had no role in the design of the study and collection, analysis, and interpretation of data and in writing the manuscript.

\section{Availability of data and materials}

The datasets generated during and/or analysed during the current study are available from the corresponding author on reasonable request.

\section{Ethics approval and consent to participate}

Institutional Review Board approval was obtained (see the "Methods" section).

Approval from the institutional animal care committee was obtained (see the "Methods" section).

\section{Consent for publication}

Written informed consent was obtained from all patients in this study.

\section{Competing interests}

The authors of this manuscript declare relationships with the following companies: BTG, Quirem Medical BV, and Terumo. J.F.W. Nijsen is co-founder and scientific director of Quirem Medical and has a minority share in the company Quirem Medical. Furthermore, Nijsen is inventor on the patents related to the $166 \mathrm{Ho}-\mathrm{PLLA}$-microspheres that are assigned to University Medical Center Utrecht Holding BV (patent numbers: W02012060707 A1 and US 2005/0201940 A1). The Department of Radiology and Nuclear Medicine of the UMC Utrecht receives royalties from Quirem Medical BV. M.G.E.H. Lam is a consultant for BTG, Quirem Medical BV, and Terumo. The Department of Radiology and Nuclear Medicine of the UMC Utrecht receives royalties from Quirem Medical BV.

\section{Author details}

${ }^{1}$ Department of Radiology and Nuclear Medicine, University Medical Center Utrecht, Utrecht, The Netherlands. ${ }^{2}$ Department of Oral and Maxillofacial Surgery, University Medical Center Utrecht, Utrecht, The Netherlands. ${ }^{3}$ Department of Clinical Sciences of Companion Animals, Faculty of Veterinary Medicine, Utrecht University, Utrecht, The Netherlands.
${ }^{4}$ Department of Head and Neck Surgical Oncology, UMC Utrecht Cancer Center, Utrecht, The Netherlands. ${ }^{5}$ Department of Radiology, Nuclear Medicine and Anatomy, Radboudumc, Nijmegen, The Netherlands.

Received: 26 July 2019 Accepted: 26 March 2020

Published online: 11 May 2020

\section{References}

1. Smits MLJ, Nijsen JFW, van den Bosch MAAJ et al (2012) Holmium-166 radioembolisation in patients with unresectable, chemorefractory liver metastases (HEPAR trial): a phase 1, dose-escalation study. Lancet Oncol 13: 1025-1034. https://doi.org/10.1016/S1470-2045(12)70334-0

2. Elschot M, Smits MLJ, Nijsen JFW et al (2013) Quantitative Monte Carlobased holmium-166 SPECT reconstruction. Med Phys 40:112502. https://doi. org/10.2967/jnumed.112.119131

3. Smits MLJ, Elschot M, van den Bosch MAAJ et al (2013) In vivo dosimetry based on SPECT and MR imaging of $166 \mathrm{Ho}$-microspheres for treatment of liver malignancies. J Nucl Med 54:2093-2100. https://doi.org/10.2967/ jnumed.113.119768

4. Prince JF, van den Bosch MAAJ, Nijsen JFW et al (2018) Efficacy of radioembolization with (166)Ho-microspheres in salvage patients with liver metastases: a phase 2 study. J Nucl Med 59:582-588. https://doi.org/10. 2967/jnumed.117.197194

5. Bakker RC, Lam MGEH, van Nimwegen SA, Rosenberg AWPJ, Van Es RJJ, Nijsen JFW (2017) Intratumoral treatment with radioactive beta-emitting microparticles: a systematic review. J. Radiat Oncol 6:323-341. https://doi. org/10.1007/s13566-017-0315-6

6. van Nimwegen SA, Bakker RC, Kirpensteijn J et al (2018) Intratumoral injection of radioactive holmium $(166 \mathrm{Ho})$ microspheres for treatment of oral squamous cell carcinoma in cats. Vet Comp Oncol 16:114-124. https:// doi.org/10.1111/vco.12319

7. Goh AS, Chung AY, Lo RH et al (2007) A novel approach to brachytherapy in hepatocellular carcinoma using a phosphorous-32 (32P) brachytherapy delivery device-a first-in-man study. Int J Radiat Oncol Biol Phys 67:786-792. https://doi.org/10.1016/j.jirobp.2006.09.011

8. Bakker RC, van Es RJJ, Rosenberg AJWP et al (2018) Intratumoral injection of radioactive holmium-166 microspheres in recurrent head and neck squamous cell carcinoma. Nucl Med Commun 1. https://doi.org/10.1097/ MNM.0000000000000792

9. Order SE, Siegel JA, Principato R et al (1996) Selective tumor irradiation by infusional brachytherapy in nonresectable pancreatic cancer: A phase I study. Int J Radiat Oncol Biol Phys 36:1117-1126. https://doi.org/10.1016/ S0360-3016(96)00484-1

10. Bult W, De Leeuw H, Steinebach OM et al (2012) Radioactive holmium acetylacetonate microspheres for interstitial microbrachytherapy: an in vitro and in vivo stability study. Pharm Res 29:827-836. https://doi.org/10.1007/ s1 1095-011-0610-7

11. Bult W, Kroeze SGC, Elschot M et al (2013) Intratumoral administration of holmium-166 acetylacetonate microspheres: antitumor efficacy and feasibility of multimodality imaging in renal cancer. PLoS One 8:e52178. https://doi.org/10.1371/journal.pone.0052178

12. Bult W, Vente MADD, Vandermeulen E et al (2013) Microbrachytherapy using holmium-166 acetylacetonate microspheres: a pilot study in a spontaneous cancer animal model. Brachytherapy 12:171-177. https://doi. org/10.1016/j.brachy.2012.08.001

13. Zielhuis SW, Nijsen JFW, De Roos R, Krijger GC, Hennink WE, van het Schip AD (2006) Production of GMP-grade radioactive holmium loaded poly $(\mathrm{L}$ lactic acid) microspheres for clinical application. Int J Pharm 311:69-74. https://doi.org/10.1016/j.jpharm.2005.12.034

14. Zielhuis SW, Nijsen JFW, Figueiredo R et al (2005) Surface characteristics of holmium-loaded poly(L-lactic acid) microspheres. Biomaterials 26:925-932. https://doi.org/10.1016/j.biomaterials.2004.03.028

15. Nijsen JFW, Seppenwoolde J-H, Havenith T, Bos C, Bakker CJ, van het Schip AD (2004) Liver tumors: MR imaging of radioactive holmium microspheres-phantom and rabbit study. Radiology 231:491-499. https://doi.org/10.1148/ radiol.2312030594

16. Beekman FJ, De Jong HWAM, Van Geloven S (2002) Efficient fully 3-D iterative SPECT reconstruction with Monte Carlo-based scatter compensation. IEEE Trans Med Imaging 21:867-877. https://doi.org/10.1109/ TMI.2002.803130 
17. LeBrun A, Joglekar T, Bieberich C, Ma R, Zhu L (2016) Identification of infusion strategy for achieving repeatable nanoparticle distribution and quantification of thermal dosage using micro-CT Hounsfield unit in magnetic nanoparticle hyperthermia. Int J Hyperthermia 32:132-143. https://doi.org/10.3109/02656736.2015.1119316

18. Chen WY, Wu CT, Wang CW et al (2018) Prognostic significance of tumorinfiltrating lymphocytes in patients with operable tongue cancer. Radiat Oncol 13:157. https://doi.org/10.1186/s13014-018-1099-6

19. Nowak T, Hupfer M, Brauweiler R, Eisa F, Kalender WA (2011) Potential of high-Z contrast agents in clinical contrast-enhanced computed tomography. Med Phys 38:6469-6482. https://doi.org/10.1118/1.3658738

20. Pietsch $\mathrm{H}$, Jost $\mathrm{G}$, Frenzel T et al (2011) Efficacy and safety of lanthanoids as $\mathrm{x}$-ray contrast agents. Eur J Radiol 80:349-356. https://doi.org/10.1016/.e.jrad.2009.10.023

21. Scott LJ, Yanch JC (1991) Absorbed dose profiles for radionuclides of frequent use in radiation synovectomy. Arthritis Rheum 34:1521-1530. https://doi.org/10.1002/art.1780341208

22. Seevinck P, Seppenwoolde J-H, de Wit T et al (2007) Factors affecting the sensitivity and detection limits of MRI, CT, and SPECT for multimodal diagnostic and therapeutic agents. anticancer agents. Anticancer Agents Med Chem 7:317-334. https://doi.org/10.2174/187152007780618153

23. Chandarana $\mathrm{H}$, Megibow AJ, Cohen B a, et al (2011) lodine quantification with dual-energy CT: phantom study and preliminary experience with renal masses. AJR Am J Roentgenol 196:W693-W700. doi: https://doi.org/10.2214/ AJR.10.5541

24. Arnolli MM, Buijze M, Franken M, de Jong KP, Brouwer DM, Broeders IAMJ (2018) System for CT-guided needle placement in the thorax and abdomen: a design for clinical acceptability, applicability and usability. Int J Med Robot 14:e1877. https://doi.org/10.1002/rcs.1877

25. Arnolli MM, Hanumara NC, Franken M, Brouwer DM, Broeders IAMJ (2015) An overview of systems for CT- and MRl-guided percutaneous needle placement in the thorax and abdomen. Int J Med Robot 11:458-475. https://doi.org/10.1002/rcs.1630

\section{Publisher's Note}

Springer Nature remains neutral with regard to jurisdictional claims in published maps and institutional affiliations.

\section{Submit your manuscript to a SpringerOpen ${ }^{\circ}$ journal and benefit from:}

- Convenient online submission

- Rigorous peer review

- Open access: articles freely available online

High visibility within the field

- Retaining the copyright to your article

Submit your next manuscript at $\boldsymbol{\nabla}$ springeropen.com 